\title{
Combined impact method in the preparatory period of the annual macrocycle of female volleyball players aged 18-19 years old
}

Roman Boichuk $^{1 \mathrm{ABCDE}}$, Sergii Iermakov ${ }^{2 \mathrm{ABCDE}}$, Oleh Vintoniak ${ }^{2 \mathrm{ADE}}$, Tatiana Yermakova ${ }^{3 \mathrm{ADE}}$

${ }^{1}$ Department of Physical Education and Sports, Ivano-Frankivsk National Technical University of Oil and Gas, Ukraine

${ }^{2}$ Department of Sport, Gdansk University of Physical Education and Sport, Poland

${ }^{3}$ Kharkiv State Academy of Design and Arts, Ukraine

Authors' Contribution: A - Study design; B - Data collection; C - Statistical analysis; D - Manuscript Preparation; E - Funds Collection.

\begin{abstract}
Background The work aim is to develop and experimentally test the combined impact method performance in the and Study Aim preparatory period of the annual macrocycle of 18-19 year old volleyball players (girls).

Material and The study involved volleyball players (girls) aged $18-19$ years old ( $n=24$, training experience -9 years). Methods Volleyball players (girls) were divided into control $(n=12)$ and experimental $(n=12)$ groups.

Results The method contributed to a higher rate of growth of most parameters of special readiness among volleyball players (girls) of the experimental group. A significant improvement in special readiness ( $p$ $<0.05$ ) was revealed for all parameters in both groups. In the experimental group, an improvement ( $p$ $<0.001$ ) was observed for 8 out of 11 parameters. In the control group, a significant improvement in the results ( $p<0.001$ ) occurred in 3 cases out of 11. A significant improvement in speed and strength training parameters ( $p<0.001$ ) was revealed: in 3 out of 4 cases (experimental group); in 1 out of 4 cases (control group). The quality of performance of the game basic techniques improved by: $4-22 \%$ ( $p<0.04-0.001$ in experimental group) $4-11 \%$ ( $<<0.05-0.02$ in control group).

Conclusions: It is advisable to devote more time to the development of more significant motor abilities of volleyball players (girls) (speed, speed and strength, dexterity and coordination). It is advisable to improve endurance in combination with the development of other motor abilities and in the process of technical and tactical improvement. In the physical training of volleyball players (girls), it is advisable to use as many training means as possible, which are similar to the main game techniques according to spatio-temporal and dynamic characteristics. Movements with load contribute to the development of intermuscular coordination and allow to quickly form the correct idea of the trained motor action.

Keywords: female volleyball players, method, abilities, macrocycle, training.
\end{abstract}

\section{Introduction}

Modern elite sport makes more and more stringent demands on athletes. The success of training athletes in modern conditions depends on the effectiveness of organization, management and control methods.

The level of sports achievements in volleyball depends on the technical, physical, psychological and tactical readiness of the athlete. To demonstrate high sports results, it is important to achieve a certain level of development of these sides of readiness and ensure their integral manifestation in the process of competitive activity $[1,2]$.

Technical training is one of the main sections of athletes training in volleyball. The process of technical improvement is associated with exceptional difficulties. This is especially true for the stage of preparation for higher achievements. The first is the need to constantly improve the technique and constantly bring it in line with the level of physical, tactical and psychological readiness. This complex interaction of different sides of an athlete's motor readiness is reflected in the process of forming and

\footnotetext{
(c) Roman Boichuk, Sergii lermakov, Oleh Vintoniak,

Tatiana Yermakova, 2021

doi:10.15561/26649837.2021.0405
}

improving motor skills of volleyball players (girls) [3, 4].

Kumar et al. [5] believe that at the present stage of development of sports games, the correct athletes training process design at the stage of preparation for higher achievements (age 17-19 years) is of great importance. At this stage, the share of special training means in the total volume of training work significantly increases. Competitive practice focused on achieving high results, is sharply increasing. The training process is characterized by the widespread use of means that can cause a stormy course of adaptation processes. It is fundamentally important that the period of the athlete's maximum predisposition to achieve high results coincides with the period of the most intense training loads [6-9].

The preparatory period in volleyball is a long-term structural unit of the training macrocycle. This is where the functional base is laid, which is necessary to cope with large volumes of special loads. These loads are aimed at direct preparation of the motor and vegetative spheres of the body for effective competitive activity. Such loads help to improve motor skills, develop physical qualities, and tactical and psychological preparation. Various tasks of special training are solved during the entire preparatory period. This approach ensures the successful performance 
of the athlete in important competitions $[2,9,10]$.

The modern training of volleyball players (girls) in the preparatory period is based on the material of exercises that create physical, mental and technical prerequisites for further special training. Exercises in nature and structure can differ significantly from competitive ones. The main task at this stage is the wide use of a variety of auxiliary and special preparatory exercises. During the preparatory period, the ratio of training means of various predominant orientation is systematically changing. At the beginning of the period, the main content of the training process is made up of fundamental (basic) exercises. Gradually, the ratio changes towards an increase in the proportion of special preparatory and competitive exercises [11, 12]. The preparatory period is divided into two stages: general preparatory and special preparatory. The ratio of the duration of these stages largely depends on the type of macrocycle and the qualifications of athletes. In the process of training highly qualified athletes, a relatively short general preparatory stage and a long special preparatory stage are usually planned. For athletes with low qualifications, the opposite ratio is reported $[13,14]$.

Zaciorskij and Kraemar [15] point to a direct connection between physical (functional) and technicaltactical readiness of volleyball players (girls). Physical training of a volleyball player shall create the level of motor qualities required for the formation of effective technique and tactics. It shall also ensure their development on a wide range of skills and abilities that are characteristic of this sport. This will allow to organically link physical fitness with motor memory. This approach contributes to the creation of the basis for the manifestation of physical qualities in a variety of motor actions that are characteristic of competitive activity in volleyball. The wider the circle of special exercises and motional actions, the more favourable the preconditions for the formation of new forms of motional activity and the improvement of those trained earlier. The combination of the processes of physical and technical training ensures the organic relationship between the sports technique and the motor qualities of volleyball players (girls) [16-18].

The method of combined impact is based on the systematic use of traditional exercises, methods and techniques in conjunction with non-traditional means - training devices and simulators [19]. This method is used in the context of sequential (physical exercises create preconditions for further development of physical qualities and mastering motor skills) and parallel (exercises simultaneously affect various components of psychomotor, conditioning and coordination abilities) impact on the physical and technical readiness of athletes [20].

Research analysis indicates the need to apply the method of combined impact in the preparatory period of the training macrocycle of 18-19 year old volleyball players (girls). This approach is a required condition for increasing the effectiveness of the competitive activity of volleyball players (girls). This determines the practical and scientific relevance of the study problem.
Hypothesis. It is assumed that the introduction of the developed methods of combined actions into the training process of volleyball players (girls) of 18-19 years old will significantly increase the level of their special preparedness and the effectiveness of competitive activity.

Study aim is to develop and experimentally test the effectiveness of the methods of combined actions in the preparatory period of the training macrocycle of 18-19 year old volleyball players (girls).

\section{Material and Methods}

Participants. The experiment involved volleyball players (girls) aged 18-19 years old $(\mathrm{n}=24$, training experience -9 years). Volleyball players (girls) were divided into control $(n=12)$ and experimental $(n=12)$ groups. The created groups were identical in terms of physical fitness and technical and tactical skills. All volleyball players (girls) provided their written consent to participate in the experiment. The study protocol was approved by the ethical committee of Ivano-Frankivsk National Technical University of Oil and Gas (Ukraine) (No. 03621 dated 03.03.2021).

Study organization. The pedagogical experiment lasted 4 months. To determine the level of physical and technical readiness of volleyball players (girls), motor tests were used [21]. Testing was carried out at the beginning and at the end of the experiment. In the study course, the level of development of speed, speed-strength abilities, special endurance, dexterity and coordination was determined:

Test 1: "92 m running with changing direction";

Test 2: "9-3-6-3-9 m running";

Test 3: "Standing long jump";

Test 4: "Standing vertical jump";

Test 5: "Running vertical jump";

Test 6: "Finger-tip push-up for 10" (s)";

Test 7: "1 Kg Overhead Medicine Ball Throw (MBT)".

To determine the level of technical and tactical readiness of volleyball players (girls), the following parameters were used:

Test 1 (fig. 1): Exercises for overhead passes with two hands from against the wall (the athlete stands with her face and then with her back to the wall). At a height of $4 \mathrm{~m}$, a control line is made on the wall. The athlete is positioned at a distance of $3 \mathrm{~m}$ from the wall. When performing the exercise, she shall strive to maintain the distance from the wall and the pass height. The athlete consistently passes the ball that bounces off the wall. The exercise sequence:

- Athlete throws the ball overhead to the wall;

- Athlete passes the ball overhead;

- Athlete returns $180^{\circ}$ (with her back to the wall) and passes the ball into the wall;

- Athlete returns $180^{\circ}$ and passes the ball into the wall (with her face to wall).

This sequence of passing the ball is one series. The maximum number of series is taken into account $[22,23]$.

Test 2 (fig. 2): Tests for the ball pass accuracy. Each player has 5 attempts. She shall serve the ball to a specific area of the court. These sites are as follows: 


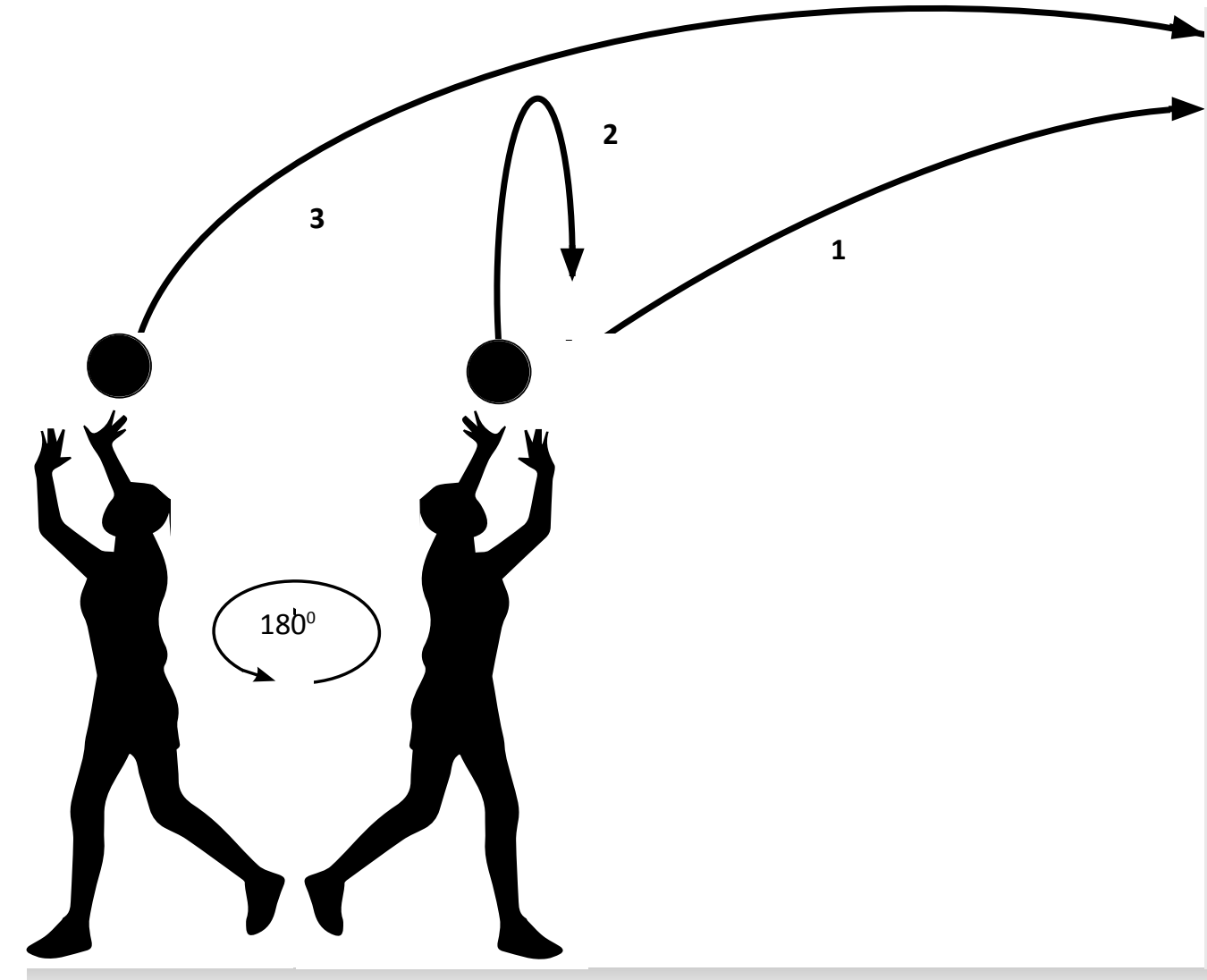

Fig. 1. Scheme of the test "Ball passing against the wall with two hands overhead"

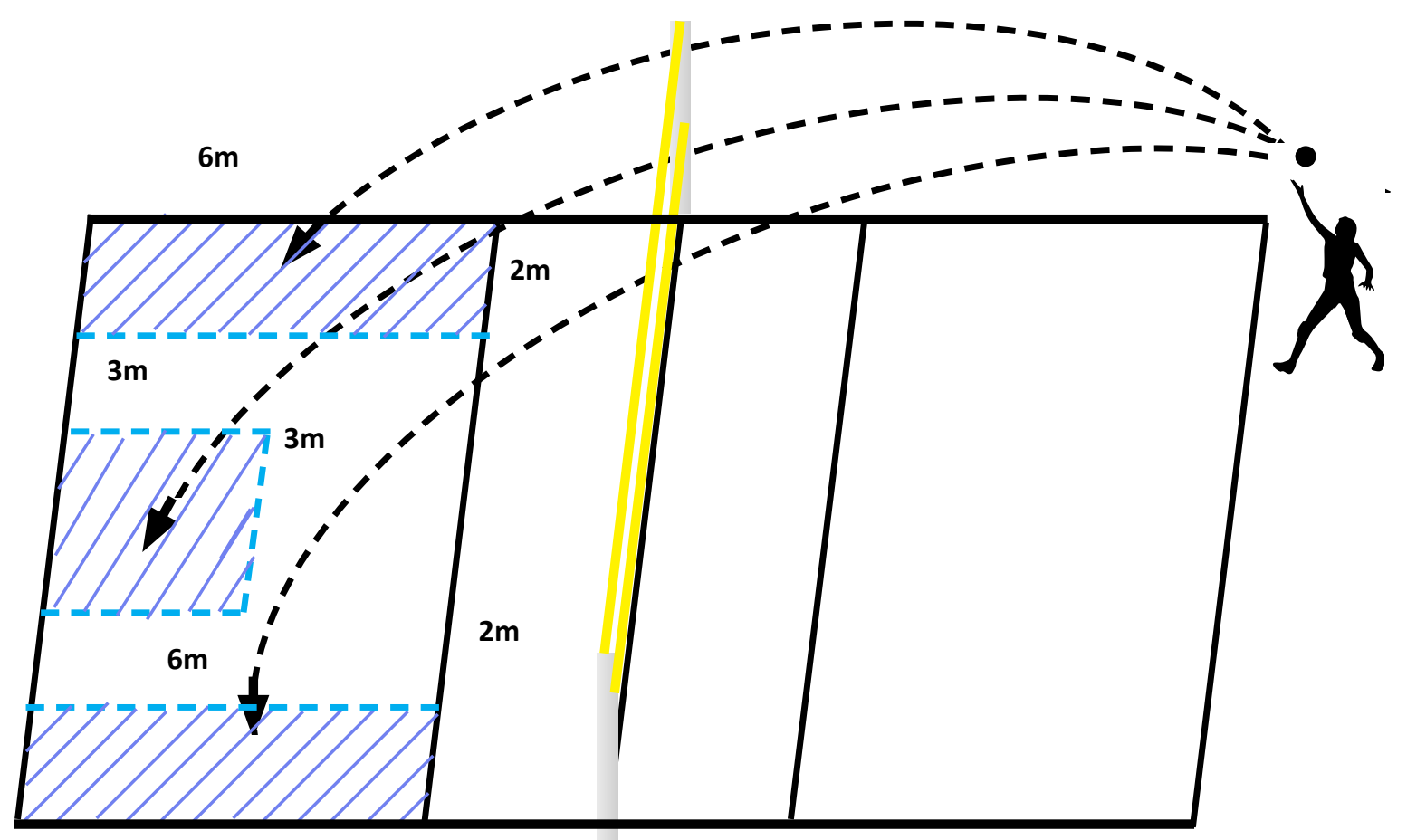

Fig. 2. Scheme of the Ball Serving Accuracy Test 
- right/left half of the court, zones 4-5 (1-2);

- $\quad$ area at the side lines in zones 5-4 (1-2); dimensions $6 \times 2 \mathrm{~m}$;

- $\quad$ area in zone 6 at the front line; dimensions $3 \times 3 \mathrm{~m}$.

Test 3 (fig. 3): Spike accuracy tests. The requirements in this test are reduced to the quality (technically correct) performance of the spike. In this case, the ball shall be sent with a certain accuracy. During spikes from zone 4 to zones $4-5$, the hit area is limited by: front, side lines, attack line at a distance of $3 \mathrm{~m}$ from the side line. During strikes from zone 4 to zone 1 , the hit area is limited by the side line and a line parallel to it at a distance of $2 \mathrm{~m}$. Athletes can use the same scheme to execute a spike from zone 2. Each player has 5 attempts.

Test 4 (fig. 4): First pass (ball reception) accuracy test. The tests are intended to determine the degree of the skill of receiving the ball after serving. A serve is made to the area where the athlete is located (only under this

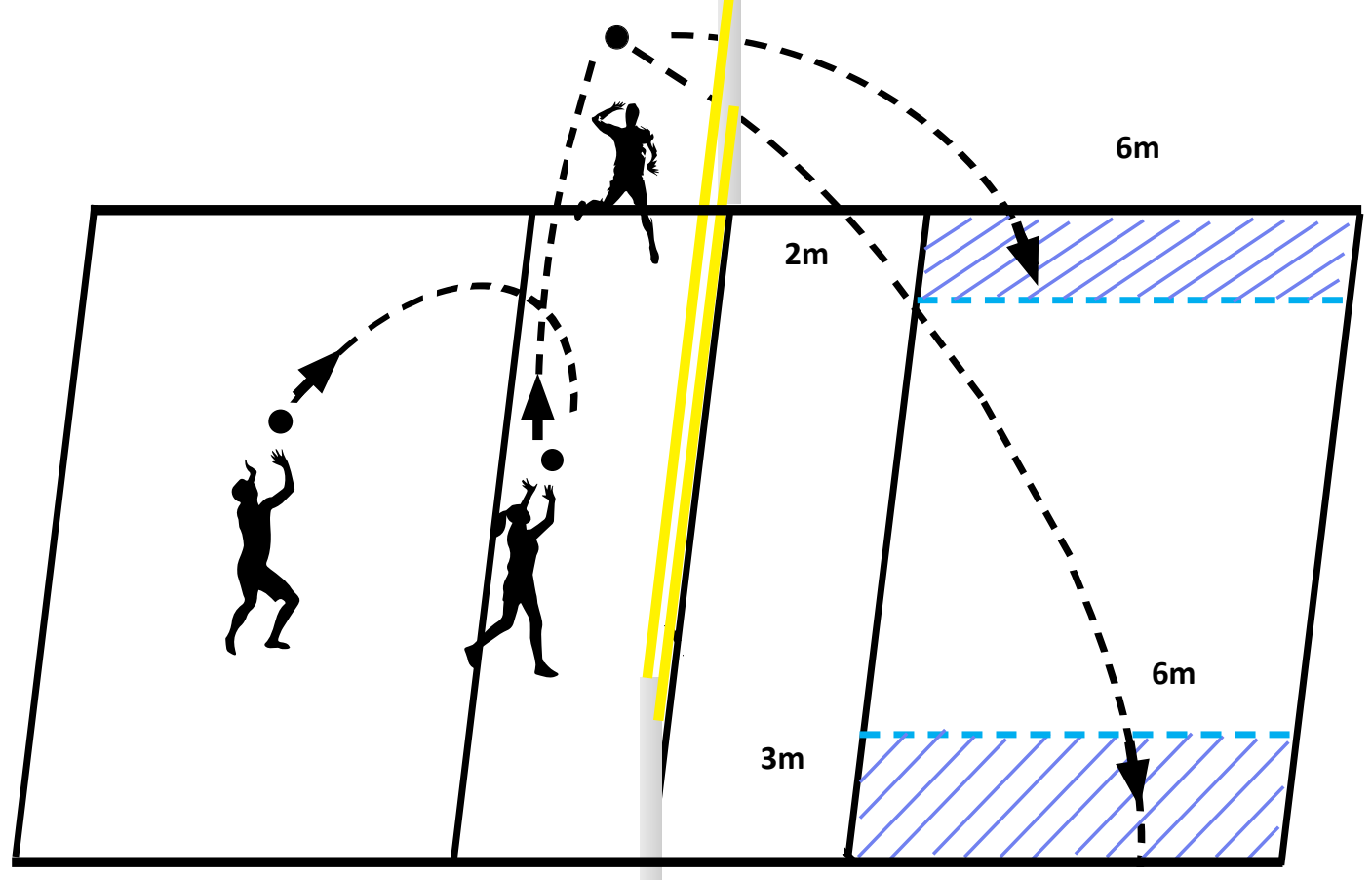

Fig. 3. Scheme of the Spike Accuracy Test

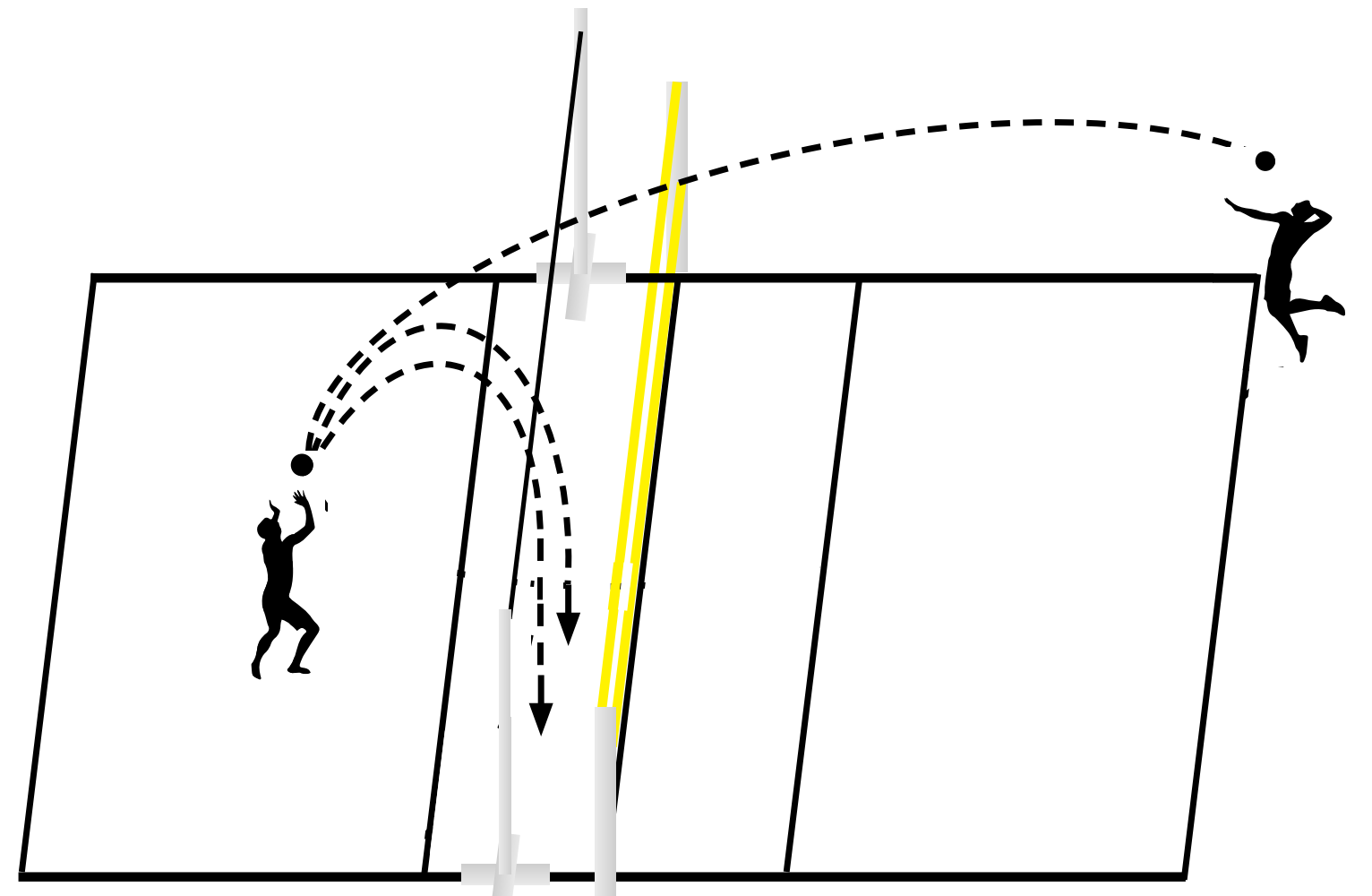

Fig. 4. Scheme of the test "Accuracy of Ball Receiving After Serving" 
condition, attempts are counted). The athlete receives the ball in zone 6 (5): the athlete shall direct the ball over the tape into zone 3 or 2 . The tape is located at a distance of $1.5 \mathrm{~m}$ from the net and at a height of $3 \mathrm{~m}$. If the ball goes outside the specified area or hits the net, then such an attempt is not counted.

The control and experimental groups trained 6 times a week for 2-2.5 hours. The content of the sessions and training loads were similar in both groups. The only exception was the method of applying combined actions, which was based on the individualization of local difficulties. In the control group, the improvement of motor abilities and technical-tactical readiness was carried out in the traditional way [19]. In the experimental group, a program of special exercises was applied. These exercises were similar in structure to the main athletic movements. The exercises fully corresponded to the regime of muscular efforts in the main phases of the motor action. Initially, these exercises were performed with great difficulty and at a slow pace. Gradually, the pace increased, and the magnitude of the difficulties decreased. At the end of such a series, the athlete received tasks: to perform a special exercise in light conditions faster and more powerfully than she performs a competitive exercise. This procedure contributed to a positive transfer of training from an auxiliary special exercise to a competitive one [24].

To develop static strength and strengthen the ligamentous-articular apparatus in the experimental group, static exercises were widely used. At the same time, the position of the body and its parts were as close as possible to those encountered in competitive activity. Also, in the training process of volleyball players (girls) of this group, the method of combined-sequential loads with different prevailing orientation of the training action were applied [25]. At the same time, the previous loads created a morpho-functional basis for the effective impact on the athlete's body of the following loads. To develop the maximum speed of movement during the spike, weight was used that did not exceed $20 \%$ of the maximum. The attention of the players was focused on the maximum movement speed. During the performance of the test for the speed of a complex reaction, adhere to the following: movements of the athletes shall exactly correspond to the competitive movements in form and muscle coordination. The athletes' attention was focused on a very abrupt onset of effort in response to a visual signal.

During the movement speed development, the fact that all its manifestations (time of a simple and complex motor reaction, individual movement speed, movements tempo) were not related to each other, was taken into account. Particular attention was paid to the development of the individual movement speed, since effective defensive play is based on it. For the local development of speed strength of individual muscle groups, two ranges of weight were used, $30-50 \%$ of the maximum (when a slight external resistance is overcome in the competition), $50-70 \%$ of the maximum (with a more significant external resistance). In order to significantly increase the spike force, both ranges were used (moreover, with different accents of motor activity in different articular angles). For the development of endurance in combination with the development of other motor abilities in the experimental group, the method of circular training was used twice a week. Usually it was 2-3 series x 10 stations (30 s of physical activity and after $30 \mathrm{~s}$ of rest). Rest between episodes for 4 minutes. Exercises of "combined" impact on coordination and conditioning abilities were also used in the experimental group. Considerable attention was paid to the improvement of coordination abilities in close connection with the improvement of technical skills.

Statistical analysis. Statistical data processing was carried out using Microsoft Excel "Data Analysis" and SPSS. For each parameter, the following was determined: arithmetic mean $(\mathrm{X})$, standard deviation $(\mathrm{S})$, standard error $(\mathrm{m})$, confidence interval $(\Delta \mathrm{x})$, assessment of the differences significance by Student's t-test with the corresponding level of significance (p). Differences were considered significant at a significance level of $p<0.05$. The Kolmogorov-Smirnov test was used to estimate the distribution parameters.

\section{Results}

Prior to the beginning of the pedagogical experiment, no statistically significant differences were found between the parameters of the experimental and control groups. It was revealed that the use of the combined actions method contributed to a higher rate of growth in the level of development of most parameters of special readiness among volleyball players (girls) of the experimental group. Significant improvement in special readiness $(p<0.05)$ was revealed in almost all parameters in both groups. However, in the experimental group an improvement ( $p$ $<0.001$ ) in 8 of 11 parameters (Table 1) was observed. In the control group, a significant improvement in results ( $p$ $<0.001$ ) occurred only in 3 cases out of 11 .

Training sessions held for 3 months (in the amount of 12-14 hours per week) resulted in a significant improvement in both groups: special endurance parameter (test "92 m running with changing direction"); special speed manifestation parameter $(p<0.001)$. It was revealed that the use of the combined impact method contributed to a higher rate of increase in the level of speed-strength abilities development in volleyball players (girls) in the experimental group. At the end of the experiment, a significant improvement $(\mathrm{p}<0.001)$ in the experimental group was revealed in 3 out of 4 parameters of speed-strength readiness. In the control group, such an improvement in results $(\mathrm{p}<0.001)$ was found in 1 out of 4 cases (Table 2 ).

The results analysis showed that the special method of combined actions resulted in a more significant increase in technical readiness parameters. For 4 parameters of technical skills (ball reception, attack, serving, passing), the volleyball players (girls) of the experimental group significantly improved $(\mathrm{p}<0.05-0.001)$ their results. The volleyball players (girls) of the control group also improved the results in this type of training. However, the significant changes were less noticeable. Significant 
Table 1. Changes in the parameters of special readiness of volleyball players (girls) of the experimental group $(n=12)$ during the pedagogical experiment

\begin{tabular}{|c|c|c|c|c|c|c|c|c|}
\hline \multirow[t]{2}{*}{$\mathbf{N}$} & \multirow[t]{2}{*}{ Parameter } & \multicolumn{2}{|c|}{$\begin{array}{l}\text { Before the } \\
\text { experiment }\end{array}$} & \multicolumn{2}{|c|}{$\begin{array}{l}\text { After the } \\
\text { experiment }\end{array}$} & \multirow[t]{2}{*}{$\Delta \mathbf{x}$} & \multirow[t]{2}{*}{$\mathbf{t}$} & \multirow[t]{2}{*}{$\mathbf{p}$} \\
\hline & & $\mathbf{x}$ & $\mathbf{s}$ & $\mathbf{x}$ & $\mathbf{s}$ & & & \\
\hline 1 & $92 \mathrm{~m}$ running with changing direction & 25.7 & 1.1 & 25.4 & 1 & 0.63 & 5.5 & 0.001 \\
\hline 2 & «9-3-6-3-9 m running», s & 8.49 & 0.48 & 8 & 0.48 & 0.28 & 9.9 & 0.001 \\
\hline 3 & «Standing long jump», s & 211 & 13.3 & 219 & 14.3 & 7.8 & 9.7 & 0.001 \\
\hline 4 & «Standing vertical jump», s & 49 & 5.9 & 52 & 5.6 & 3.5 & 6.2 & 0.001 \\
\hline 5 & Running vertical jump, s & 53 & 6.9 & 57 & 6.9 & 4.1 & 7.5 & 0.001 \\
\hline 6 & Finger-tip push-up for $10 \mathrm{~s}$ & 10.7 & 1.8 & 12.7 & 2.2 & 1.1 & 4 & 0.002 \\
\hline 7 & $\begin{array}{l}1 \text { Kg Overhead Medicine Ball Throw } \\
\text { (MBT)"; }\end{array}$ & 13.9 & 1.3 & 15 & 1.3 & 0.8 & 6.9 & 0.001 \\
\hline 8 & Ball passes (alternation) & 9.6 & 2.2 & 10 & 2.6 & 1.3 & 2.4 & 0.038 \\
\hline 9 & Ball serving & 3 & 0.9 & 3.8 & 0.9 & 0.53 & 6.7 & 0.001 \\
\hline 10 & Spike & 3.2 & 0.6 & 4.1 & 0.9 & 0.36 & 5.6 & 0.001 \\
\hline 11 & Ball reception after serving & 3.1 & 0.7 & 3.7 & 1 & 0.41 & 4.2 & 0.002 \\
\hline
\end{tabular}

Table 2. Changes in the parameters of special readiness in volleyball players (girls) of the control group $(n=12) d u r i n g$ the pedagogical experiment

\begin{tabular}{|c|c|c|c|c|c|c|c|c|}
\hline \multirow[t]{2}{*}{$\mathbf{N}$} & \multirow[t]{2}{*}{ Parameter } & \multicolumn{2}{|c|}{$\begin{array}{l}\text { Before the } \\
\text { experiment }\end{array}$} & \multicolumn{2}{|c|}{$\begin{array}{l}\text { After the } \\
\text { experiment }\end{array}$} & \multirow[t]{2}{*}{$\Delta \mathbf{x}$} & \multirow[t]{2}{*}{$\mathbf{t}$} & \multirow[t]{2}{*}{$\mathbf{p}$} \\
\hline & & $x$ & $\mathbf{s}$ & $\mathbf{x}$ & $\mathbf{s}$ & & & \\
\hline 1 & $92 \mathrm{~m}$ running with changing direction & 26.8 & 1.07 & 26.6 & 1.2 & 0.6 & 2.97 & 0.014 \\
\hline 2 & «9-3-6-3-9 m running», s & 8.88 & 0.48 & 8.71 & 0.55 & 0.28 & 6.33 & 0.001 \\
\hline 3 & «Standing long jump», s & 207 & 15.4 & 209 & 15.6 & 9.1 & 5.16 & 0.001 \\
\hline 4 & «Standing vertical jump», s & 43.2 & 8.1 & 44.2 & 8.4 & 4.8 & 2.47 & 0.033 \\
\hline 5 & Running vertical jump, s & 47.3 & 8.2 & 48.4 & 8.6 & 4.8 & 3.83 & 0.003 \\
\hline 6 & Finger-tip push-up for $10 \mathrm{~s}$ & 11.4 & 2 & 12.1 & 2.2 & 1.19 & 2.67 & 0.024 \\
\hline 7 & $\begin{array}{l}1 \text { Kg Overhead Medicine Ball Throw } \\
\text { (MBT)"; }\end{array}$ & 14.4 & 0.75 & 14.7 & 0.85 & 0.57 & 5.8 & 0.001 \\
\hline 8 & Ball passes (alternation) & 9 & 1.8 & 9.4 & 2.4 & 1.08 & 1.79 & 0.104 \\
\hline 9 & Ball serving & 3.2 & 0.9 & 3.6 & 1.3 & 0.51 & 2.2 & 0.05 \\
\hline 10 & Spike & 3.5 & 1.03 & 3.9 & 1.2 & 0.61 & 2.9 & 0.016 \\
\hline 11 & Ball reception after serving & 3.3 & 0.9 & 3.6 & 1.1 & 0.49 & 2.4 & 0.038 \\
\hline
\end{tabular}

improvement $(\mathrm{p}<0.05)$ was found for 3 parameters. There was no statistically significant improvement in the results of the test "Alternation When Ball Passing to the Wall with Two Hands Overhead" in the control group volleyball players (girls) ( $\mathrm{p}>0.05)$.

\section{Discussion}

A high level of playing technique is the determining factor in the competitive activity of volleyball players (girls). According to Bernstein [26], there is a certain functional relationship between the level of development of motor abilities and the degree of motor skills mastery. Taking into account the leading role of the content in relation to the form, experts adhere to the position of the leading role of motor abilities. Hence it follows that the formation of skills can be successful only if this process is preceded by the process of purposeful development of motor abilities [27, 28]. Therefore, the organic relationship of physical and technical training of volleyball players (girls) is considered as one of the leading principles of sports improvement. Its essence lies in the fact that the purposeful development of motor abilities simultaneously contributes to the improvement of sports technique. This requires the selection of special exercises, similar in structure and nature of execution to the main exercise. Obviously, this contributes to the unity of the development of special abilities and skills [29-32].

After the pedagogical experiment, a significant 
improvement in the parameters was revealed, characterizing the level of development of most of the motor abilities of volleyball players (girls) in both groups $(\mathrm{p}<0.05)$. This can be explained by the fact that in the preparatory period there is a large volume of training loads of general developmental orientation. In this regard, Zaciorskij et al. [15] and Platonov [12] note that at this stage the foundation of physical and functional readiness of volleyball players (girls) is created. At this stage special training is based. The authors also emphasize that the partial tasks of this stage are versatile physical development and health promotion, further development of the strength of various muscle groups, stimulation of recovery processes, and improvement of psychological readiness.

The conducted studies showed a more reliable increase in speed-strength abilities in volleyball players (girls) of the experimental group. In our opinion, this is a consequence of the use of special weight in the process of developing the strength of various muscle groups, taking into account the individual characteristics of volleyball players (girls). Also, the distribution of time for the development of motor abilities significantly influenced the final result. In this group, the endurance was developed in combination with the development of other motor abilities and in the process of tactical and technical improvement. Time for the development of this quality was directed to improve speed-strength readiness. In contrast, the control group had separate time for endurance development. The obtained results of the study confirmed the opinion and experimental data of other authors [33-35] about the prevailing development of certain types of motor abilities according to their importance in the structure of special readiness of volleyball players (girls).

If we talk about changes in technical readiness parameters, they turned out to be more significant in the experimental group. The quality of performing the basic techniques of playing volleyball players (girls) from the experimental group improved by $4-22 \%$ ( $p<0.04$ $0.001)$. While the improvement of these techniques among volleyball players (girls) of the control group occurred by $4-11 \%(p<0.05-0.02)$. In addition, the increase in the efficiency of ball passing in the control group was not significant ( $p>0.05$ ). We see the reason for a more significant improvement in technical readiness parameters among volleyball players (girls) in the experimental group in the wide use of special physical training means. These exercises were similar to the main techniques not only in structure, but also in the regimen of muscular efforts in the main phases of the motor action. In addition, in the experimental group, the improvement of coordination abilities occurred in close connection with the improvement in the techniques implementation. The choice of these areas of sports training is consistent with the recommendations of other studies [36-38]. Modern researchers recommend using weights as a way of additional mobilization of analysers to improve special physical and technical readiness, increase coordination abilities. Weighted movements contribute to the development of intermuscular coordination, which is required for the rational organization of dynamic accents of the motor action coordination structure. Complications contribute to additional excitation of the corresponding nerve centers and an increase in the number of motor units involved in the work of muscles. Optimal weighted movement reduces the variability of the structure of muscle work and brings it closer to the most rational pattern. The authors argue that the use of weights contributes to a faster formation of correct ideas about the motor action being trained. As a consequence, this approach contributes to a faster mastery of the game technique elements in general [20,39].

In our opinion, the data obtained on a significant improvement in the parameters of speed-strength and technical readiness of volleyball players (girls) indicate the importance of using combined consecutive weights. This method provided for their consistent growth. At the same time, training means were selected that reflected the structural features of techniques. They created a morpho-functional basis for the effective impact on the athlete's body of the following more specialized training influences. The intensification of the organism's work regime provided for morphological and other quantitative and qualitative changes, which form the basis of its longterm adaptation to the conditions of sports activity. Such changes make it possible to stabilize the functionality of volleyball players (girls) at the achieved level. They act as prerequisites for their further improvement $[18,36]$. This can be fully ensured only with such an organization of physical training, taking into account the specific patterns of the organism development process of adaptation to this mode of muscular work [40]. It is necessary to approach the solution of improving the movements technique issues of a volleyball player taking into account the organic relationship of physical and technical sides of motor activity, individual characteristics of an athlete [41, 42]. After all, the close interaction of these two sides of the athletes' readiness is conditioned by biomechanical, anatomical, physiological patterns, commonality of the reflex mechanism underlying the athlete's motor skills and motor abilities. Moreover, this relationship takes different forms, different quantitative and qualitative features, which differ significantly in different sports and at different stages of technical mastery [43].

Thus, the results obtained by us allow us to reveal the comparative effectiveness of two methods of planning the process of training volleyball players (girls) for the competitive season. At the same time, priority should be given to the improvement of more significant types of motor abilities and to the selection of training means that are similar to the competitive exercise in form and content. This approach will contribute to the maximum manifestation of the volleyball player's entire motor potential in the process of playing activity. Along with this, further studies are required to experimentally test various options for constructing the process of preparing volleyball players (girls) for the playing season. It seems that it is necessary to pay more attention to the development 
of training means for the development of those muscle groups that are directly involved in the implementation of the volleyball technique elements. This will help to improve the techniques effectiveness and prevent injury.

\section{Conclusions}

1. In the preparatory period of the annual training cycle, it is advisable to devote more time to the development of the motor abilities of volleyball players (girls), which are more significant for successful game activity (speed, speed-strength, dexterity and coordination). It is advisable to improve endurance in combination with the development of other motor abilities and in the process of technical and tactical improvement.

2. In the process of physical training of volleyball players (girls), it is advisable to use as many training means, which are similar to the basic techniques of playing volleyball in terms of spatio-temporal and dynamic characteristics, as possible. During the reaction speed development in volleyball players (girls), it is recommended to use movements that are similar to those of competition in form and muscle coordination.

3 . Weighted movements contribute to the development of intermuscular coordination and allow to quickly form the correct idea of the motor action being trained. The method of combined impact is advisable to be used in the context of sequential and parallel impact on the physical and technical fitness of athletes.

\section{Acknowledgments}

The article authors are grateful to Mestechkin Vadym for his help in the manuscript preparation.

\section{Conflict of interests}

The authors declare that there is no conflict of interests.

\section{References}

1. Natali S, Ferioli D, La Torre A, Bonato M. Physical and technical demands of elite beach volleyball according to playing position and gender. Journal of Sports Medicine and Physical Fitness. 2019;59(1):6-9. https://doi.org/10.23736/s0022-4707.17.07972-5

2. Pelzer $T$, Schmidt $M$, Jaitner $T$, Pfeiffer M. External training load and the effects on training response following three different training sessions in young elite beach volleyball players. International Journal of Sports Science \& Coaching. 2020;15(5-6):717-727. https://doi.org/10.1177/1747954120940488

3. Paz GA, Gabbett TJ, Maia MF, Santana H, Miranda H, Lima V. Physical performance and positional differences among young female volleyball players. The Journal of Sports Medicine and Physical Fitness, 2017;57(10):1282-1289. https://doi.org/10.23736/S0022-4707

4. Trajkovic N, Kristicevic T, Sporis G. Small-sided games vs. instructional training for improving skill accuracy in young female volleyball players. Acta Kinesiologica, 2017;11(2):72-76.

5. Kumar G, Shukla A, Chhoker A, Thapa R K. Identification of Factors Determining Winning in Men's and Women's Beach Volleyball: a Logistical Regression Approach. Teorîa ta Metodika Fìzičnogo Vihovannâ, 2021;21(1):26-35. https://doi.org/10.17309/tmfv.2021.1.04

6. Boichuk R, Iermakov S, Kovtsun V, Pasichnyk V, Melnyk V, Lazarenko M, Troyanovska M, Kovtsun V. Effect of physical development parameters and conditioning abilities on the level of motor coordination in female volleyball players in the phase of specialized basic training. Journal of Physical Education and Sport, 2018;18(4):1950-1957. https://doi.org/10.7752/jpes.2018.s4288

7. Fathi A, Hammami R, Moran J, Borji R, Sahli S, Rebai H. Effect of A 16 Week Combined Strength and Plyometric Training Program Followed by A Detraining Period on Athletic Performance in Pubertal Volleyball Players. Journal of strength and Conditioning Research, 2019;33(8):2117-2127. https://doi.org/10.1519/JSC.0000000000002461

8. Pelzer T, Schmidt M, Jaitner T, Pfeiffer M. External training load and the effects on training response following three different training sessions in young elite beach volleyball players. International Journal of Sports Science \& Coaching, 2020;15(5-6):717-727. https://doi.org/10.1177/1747954120940488

9. Gram MCD, Clarsen B, Bø K. Injuries and illnesses among competitive Norwegian rhythmic gymnasts during preseason: a prospective cohort study of prevalence, incidence and risk factors. British Journal of Sports Medicine, 2021;55:231-236. https://doi.org/10.1136/bjsports-2020-102315

10.Martins FAS, dos Santos AB, da Silva LA, Martins JCL. Electromiographic analysis of femoral quadriceps in futsal and volleyball amateur athletes. Rev Bras Futsal Futeb. 2020;12(47):153-159.

11.Izadi M,Arazi H, Ramirez-Campillo R, Mirzaei M, Saidie P. Inseason in-field variable resistance training: effects on strength, power, and anthropometry of junior soccer players. Journal of Sports Medicine and Physical Fitness, 2020;60(2):220-228. https://doi.org/10.23736/S0022-4707.19.09937-7

12.Platonov VN. Motor qualities and physical training of athletes. Kyiv: Olympic literature, 2017. (in Russian).

13. Clemente FM, Mendes B, Palao JM, Silvério A, Carriço S, Calvete F, Nakamura FY. Seasonal player wellness and its longitudinal association with internal training load: study in elite volleyball. Journal of Sports Medicine and Physical Fitness, 2019;59(3):345-351. https://doi.org/10.23736/S0022-4707.18.08312-3

14.Duarte TS, Coimbra DR, Miranda R, et al. Monitoring training load and recovery in volleyball players during a season. Rev Bras Med Esporte, 2019;25:226-229. https://doi.org/10.1590/1517-869220192503195048

15.Zaciorskij VM, Kraemar WJ. Science and Practice of Strength Training. Champaign, IL: Human Kinetics; 2006.

16.Nakano N, Inaba Y, Fukashiro S, Yoshioka S. Basketball players minimize the effect of motor noise by using near-minimum release speed in free-throw shooting. Human Movement Science. 2020; 70:102583. https://doi.org/10.1016/j.humov.2020.102583

17.Bandakov MP, Sannikova AV. A Methodological Approach to Differentiating Means of Development of Coordination Abilities in Ski-Racers. Human. Sport. Medicine, 2020;20 (1):82-88. https://doi.org/10.14529/hsm200110

18.Kutac P, Zahradnik D, Krajcigr M, Bunc V. The effect of long-term volleyball training on the level of somatic parameters of female volleyball players in various age categories. Peerj. 2020;8. https://doi.org/10.7717/peerj.9992 
19.Guba VP, Bulykina LV, Pustoshilo PV. Volleyball: bases of preparation, training, refereeing. Moscow: Sport; 2019. (in Russian)

20.Denisov MV. Adjoint method as a factor contributing to the optimization of the process of improving elements in volleyball. Theory and Practice of Physical Culture, 2007;4:40-41. (in Russian).

21.Morrow JR, Mood DP, Disch JG, Kang M. Measurement and evaluation in human performance (5 ${ }^{\mathrm{rd}} \mathrm{ed}$.), Champaign, IL: Human Kinetics; 2016.

22.Zhelezniak IuD, Portnov IuM, Savin VP. Sport games. Technique, tactic, training. Moscow: Academy; 2001. (in Russian).

23.Tabatabaei SM, Daneshmandi H, Norasteh AA, Sharif Nia H. Development of Screening Test Battery for Volleyball Players: A Mixed Method Study. Physical Treatments, 2017;7(3):163-174. http://dx.doi.org/10.32598/ptj.7.3.163

24.Ramirez-Campillo R, García-de-Alcaraz A, Chaabene H, Moran J, Negra Y, Granacher U. Effects of Plyometric Jump Training on Physical Fitness in Amateur and Professional Volleyball: A MetaAnalysis. Frontiers Physiology, 2021; 12:636140. https://doi.org/10.3389/fphys.2021.636140

25.Fuchs PX, Fusco A, Cortis C, Wagner H. Effects of Differential Jump Training on Balance Performance in Female Volleyball Players. Applied Sciences, 2020;10(17):5921. https://doi.org/10.3390/app10175921

26.Bernstein NA. The coordination and regulation of movements. Oxford: Pergamon Press; 1967.

27.ZerfM, Hadjar Kherfane M, Kohli K, Louglaib L. Relationship Between Maximum Aerobic Speed Performance and Volleyball Game Motor Power-Explosive Abilities. Teoriâ ta Metodika Fìzičnogo Vihovannâ, 2019;19(4):179-185. https://doi.org/10.17309/tmfv.2019.4.03

28.Wang M-H, Chen K-C, Hung M-H, Chang C-Y, Ho C-S, Chang C-H, Lin K-C. Effects of Plyometric Training on Surface Electromyographic Activity and Performance during Blocking Jumps in College Division I Men's Volleyball Athletes. Applied Sciences. 2020;10(13):4535. https://doi.org/10.3390/app10134535

29.Boichuk R, Iermakov S, Kovtsun V, Levkiv V, Karatnyk I, Kovtsun V. Study of the correlation between the indicators of psychophysiological functions and coordination preparedness of volleyball players (girls) at the age of 15-17. Journal of Physical Education and Sport, 2019; 19(Supplement issue 2):405-412. https://doi.org/10.7752/jpes.2019.s2060

30.Vilela G, Caniuqueo-Vargas A, Ramirez-Campillo R, Hernandez-Mosqueira C, da Silva SF. Effects of plyometric training on explosive strength in pubescent girls volleyball players. Retos-Nuevas Tendencias En Educacion Fisica Deporte Y Recreacion. 2021(40):41-46.

31.García-de-Alcaraz A, Ramírez-Campillo R, RiveraRodríguez M, Romero-Moraleda B. Analysis of jump load during a volleyball season in terms of player role. Journal of Sports Science and Medicine Sport, 2020;23(10):973-978. https://doi.org/10.1016/j.jsams.2020.03.002
32.Pas Himfl, Pluim BM, Kilic O, Verhagen E, Gouttebarge V, Holman R, et al. Effectiveness of an e-health tennisspecific injury prevention programme: randomised controlled trial in adult recreational tennis players. British Journal of Sports Medicine, 2020;54:1036-1041. https://doi.org/10.1136/bjsports-2019-101142

33.Serin E, Ziyagil MA. The effect of 8 Weeks squat exercise program on body composition in young males. International Journal of Disabilities Sports and Health Sciences, 2020;3(1):28-32. https://doi.org/10.33438/ijdshs.716858

34.Poperekov VS, Buldakova NV, Bandakov MP, Zhilina NO, Solgalov VS. Focused Development of Jumping Ability in Young Basketball Players by Means of Circuit Training. Human. Sport. Medicine, 2018;18 (4):103-109. https://doi.org/10.14529/hsm180415

35.Ramirez-Campillo R, Andrade DC, Nikolaidis PT, Moran J, Clemente FM, Chaabene H, Comfort P. Effects of Plyometric Jump Training on Vertical Jump Height of Volleyball Players: A Systematic Review with Meta-Analysis of RandomizedControlled Trial. Journal of Sports Science and Medicine, 2020;19(3):489-499.

36.Lyakh VI, Sadowski J, Witkowski Z. Development of coordination motor abilities (CMA) in the system of long-term preparation of athletes. Polish Journal of Sport and Tourism, 2011;18(3):187-197. https://doi.org/10.2478/v10197-011-0014-6

37.Vaz DV, Avelar BS, Resende RA, Effects of attentional focus on movement coordination complexity. Human Movement Science, 2019;64:171-180. https://doi.org/10.1016/j.humov.2019.01.012

38.Soylu C, Altundağ E, Akarçeşme C, Ün Yıldırım N. The relationship between isokinetic knee flexion and extension muscle strength, jump performance, dynamic balance and injury risk in female volleyball players. Journal of Human Sport and Exercise, 2020;15(3):502-514. https://doi.org/10.14198/jhse.2020.153.03

39.Cieminski K. The efficiency of executing technical actions in volleyball and the teams' gender and sports level. Trends in Sport Sciences, 2018;3(25):159-165. https://doi.org/10.23829/TSS.2018.25.3-6

40.Oliveira Ldos S, Moura TBMA, RodackiALF, Tilp M, Okazaki VHA. A systematic review of volleyball spike kinematics: Implications for practice and research. International Journal of Sports Science \& Coaching, 2020;15(2):239-255. https://doi.org/10.1177/1747954119899881

41.Michalopoulos G, Sotiropoulos Soti K, Dricos S, Barzouka K, Angelonidis Y. Spatiotemporal analysis of setting per game complex and team rotation in junior volleyball. Trends in Sport Sciences, 2020;27(3):141-148. https://doi.org/10.23829/TSS.2020.27.3-4

42.Rubajczyk K and Rokita A. The Relative Age Effect and Talent Identification Factors in Youth Volleyball in Poland. Frontiers Physiology, 2020;11:1445. https://doi.org/10.3389/fpsyg.2020.01445

43.Kilic K, Ince ML. Youth athletes' developmental outcomes by age, gender, and type of sport. Journal of Human Sport and Exercise, 2021;16(1):212-225. https://doi.org/10.14198/jhse.2021.161.19 


\section{Information about the authors:}

Roman Boichuk; (Corresponding author); https://orcid.org/0000-0001-7377-6211; roman-boychuk@ukr.net; Department of Physical Education and Sports, Ivano-Frankivsk National Technical University of Oil and Gas, 15 Karpatska Str., Ivano-Frankivsk, 76019, Ukraine.

Sergii lermakov; http://orcid.org/0000-0002-5039-4517; sportart@gmail.com; Department of Sports, Gdansk University of Physical Education and Sport; Kazimierza Górskiego 1, 80-336 Gdańsk, Poland.

Oleh Vintoniak; https://orcid.org/0000-0003-4940-1238; sport@nung.edu.ua; Department of Physical Education and Sports, Ivano-Frankivsk National Technical University of Oil and Gas, 15 Karpatska Str., Ivano-Frankivsk, 76019, Ukraine.

Tatiana Yermakova; https://orcid.org/0000-0002-3081-0229; yermakova2015@gmail.com; Department of Pedagogy, Kharkiv State Academy of Design and Arts; Kharkiv, Ukraine.

Cite this article as:

Boichuk R, lermakov S, Vintoniak O, Yermakova T. Combined impact method in the preparatory period of the annual macrocycle of female volleyball players aged 18-19 years old. Pedagogy of Physical Culture and Sports, 2021;25(4):234-243. https://doi.org/10.15561/26649837.2021.0405

This is an Open Access article distributed under the terms of the Creative Commons Attribution License, which permits unrestricted use, distribution, and reproduction in any medium, provided the original work is properly cited (http://creativecommons.org/licenses/by/4.0/deed.en).

Received: 15.04 .2021

Accepted: 01.06.2021; Published: 30.08.2021 